\title{
Caring dan Observing Orang Tua Kepada Anak
}

\author{
Yuarini Wahyu Pertiwi ${ }^{1}$, Hema Dayita Pohan ${ }^{1}$, Erik Saut H Hutahaean ${ }^{1}$, Djuni Thamrin ${ }^{2}$, \\ Tiara Anggita Perdini 1,* \\ ${ }^{1}$ Fakultas Psikologi; Universitas Bhayangkara Jakarta Raya; Jl. Perjuangan 081, Marga Mulya, \\ Bekasi Utara; 02188955882/ +622188955871; e-mail: yuarini.wp@dsn.ubharajaya.ac.id, \\ hema.dayita@dsn.ubharajaya.ac.id, erik.saut@dsn.ubharajaya.ac.id, \\ tiaraanggitaperdini@gmail.com \\ 2 Fakultas Ekonomi; Universitas Bhayangkara Jakarta Raya; Jl. Perjuangan 081, Marga \\ Mulya, Bekasi Utara; 02188955882/ +622188955871; e-mail: \\ djuni.thamrin@dsn.ubharajaya.ac.id \\ *Korespondensi: e-mail: tiaraanggitaperdini@gmail.com
}

\begin{abstract}
RPTRA is a community established by the DKI Jakarta government in order to improve the quality of life of its citizens, which in this case is specifically to support the growth and development of children, the comfort of parents and the comfort of its citizens in interacting. Children's growth and development is a mandatory thing that must be considered by parents, therefore the role of parents in providing care is important. In providing care, parents must have good care and observation of their children. If parents pay less attention and care to their children, it is feared that children will have difficulty in completing their developmental tasks. At this community service activity, the implementing team will provide material presentations about care and attention that will be conveyed through the lecture method. The results show that there are many variants of answers from the participants regarding parenting, the participants also better understand how to be parents who care and pay attention to their children. This activity still has limitations in the form of small stimuli, because the material provided is still only providing additional knowledge to parents. Follow-up activities are still needed so that parents can also apply knowledge effectively to their children. Then for the government, especially the RPTRA administrators, it is hoped that they can hold programs that can increase the bond between parents and children.
\end{abstract}

Keywords: Children, Parents, Caring, Observing, Parenting

\begin{abstract}
Abstrak
RPTRA merupakan komunitas yang didirikan oleh pemerintah DKI Jakarta guna untuk meningkatkan kualitas hidup para warganya yang dalam hal ini khusus kepada mendukung tumbuh kembang anak, kenyaman orang tua serta kenyamanan warganya dalam berinteraksi. Tumbuh kembang anak merupakan hal wajib yang harus diperhatikan oleh para orang tua, oleh karena itu peran orang tua dalam memberikan pengasuhan merupakan hal penting. Dalam memberikan pengasuhan, orang tua harus memiliki kepedulian dan pengamatan yang baik terhadap anak-anaknya. Apabila orang tua kurang memperhatikan dan peduli kepada anaknya, maka dikhawatirkan anak akan kesulitan dalam menyelesaikan tugas-tugas perkembangannya. Pada kegiatan pengabdian masyarakat kali ini tim pelaksana akan memberikan pemaparan materi mengenai kepedulian dan perhatian yang akan disampaikan melalui metode ceramah. Hasilnya menunjukan banyak varian jawaban dari para peserta kegiatan mengenai pengasuhan, para peserta pun lebih memahami bagaimana menjadi orang tua yang peduli dan memperhatikan anak. Kegiatan ini masih memiliki keterbatasan berupa rangsangan kecil, karena materi yang diberikan masih sekedar memberikan tambahan pengetahuan kepada orang tua. Kegiatan lanjutan masih diperlukan agar orang tua juga dapat mempraktekan
\end{abstract}



Perdini

pengetahuan secara efektif kepada anak-anaknya. Kemudian bagi pemerintah khususnya para pengurus RPTRA, diharapkan dapat mengadakan program-program yang dapat meningkatkan kelekatan orang tua dan anak.

Kata kunci: Anak-Anak, Orang Tua, Kepedulian, Perhatian, Pengasuhan

\section{Pendahuluan}

Keluarga merupakan tempat untuk anak berkembang dan untuk pertama kalinya mengenal dunia (Winnicott, 2021). Melalui keluarga, seorang anak belajar untuk tumbuh berkembang menjadi pribadi yang matang, dimana hal ini merupakan salah satu kewajiban orang tua (Moore, 2017). Sesuai dengan tujuan tersebut maka berdirilah komunitas bernama RPTRA (Ruang Publik Terpadu Ramah Anak). Komunitas ini dibangun oleh pemerintah provinsi DKI Jakarta dengan tujuan untuk meningkatkan kualitas hidup bagi warga Jakarta. RPTRA merupakan ruang publik berupa ruangan terbuka hijau yang asri ramah anak yang dilengkapi fasilitas lainnya seperti taman bermain anak, lapangan olahraga, tanaman serta pusat kompos, dan masih banyak lagi. Melalui pemberian fasilitas tersebut diharapkan dapat mendukung tumbuh kembang anak, kenyamanan orang tua serta kenyamanan dalam berinteraksi ("Ruang Publik Terpadu Ramah Anak (RPTRA)," 2020).

Perkembangan merupakan urutan tahapan perubahan jasmani dan rohani individu menuju kearah yang lebih maju serta semakin sempurna (Benson, Roehlkepartain, \& Rude, 2003). Perkembangaan yang terjadi pada anak meliputi aspek fisik dan psikologis yang terjadi secara sistematis, terprogresif, dan saling berhubungan artinya perubahan fisik dan psikologis terjadi secara meningkat dan teratur (Suteja, 2017). Adapun periode atau tahapan perkembangan anak meliputi prenatal, infancy, early childhood, middle and late childhood dan tahapan remaja (John W. Santrock, 2012). Semua urutan tahapan tersebut memiliki tugas perkembangan masing-masing dan perlu dilewati individu dengan baik. Menurut Havighurst (dalam J.W Santrock, 2003) tugas perkembangan adalah suatu hal yang muncul pada periode tertentu dalam rentang kehidupan individu. Apabila individu berhasil pada satu tugas perkembangan akan membawa kebahagiaan dan kesuksesan serta mempersiapkan diri untuk tugas perkembangan selanjutnya. Namun, bila individu gagal dalam tugas perkembangan tertentu, maka akan menyebabkan ketidakbahagiaan dan kekecewaan pada individu dan kemudian akan mengalami kesulitan dalam menuntaskan tugas perkembangan selanjutnya. Oleh karena itu peran orang tua dalam memberikan pengasuhan kepada anak sangat penting (Hutahaean, Nugraha, Perdini, Bastoro, \& Marbun, 2020). Sebagai orang tua penting untuk mengetahui tugas perkembangan anak agar dapat memberikan usaha yang maksimal dalam perkembangannya, apabila setiap aspek bisa berkembang secara baik maka anak dapat menjalankan tugas perkembangan dengan baik juga (Khaulani, Neviyarni, \& Murni, 2020). Bagaimana agar orang tua mengetahui pengasuhan yang tepat? Yaitu dengan Kepedulian (caring), dan Pengamatan (observing). 
Orang tua dalam mengasuh anak harus didasari dengan kepedulian (Holcomb, Latham, \& Fernandez-Baca, 2015). Orang tua yang peduli berarti adalah orang tua yang berusaha semaksimal mungkin memenuhi kebutuhan anak terutama kepada kebutuhan dasar anak (Lafollette, 2010). Menurut Susanti \& Koswara (2019) terdapat tiga kelompok kebutuhan dasar pada anak, yang pertama yaitu asah dimana hal ini mengarah kepada kebutuhan stimulasi mental seperti rangsangan dan dorongan, rangsangan menjadi dasar dalam memenuhi proses belajar anak dan tertuju kepada mental dan psikososialnya seperti kecerdasan, keterampilan, kemandirian, dan lain-lain. kedua yaitu asih, dimana hal ini mengarah kepada kebutuhan emosi dan kasih sayang yang didalamnya tercakup hubungan erat, mesra dan juga selaras, hal ini juga salah satu dasar mutlak untuk menjamin tumbuh kembang yang maksimal. ketiga yaitu asuh, hal ini mengarah kepada kebutuhan fisikal, gizi, perawatan kesehatan dasar dan pengobatan, tempat tinggal, pakaian dan lain-lain. Dalam menyampaikan kepeduliaanya, orang tua harus menggunakan Bahasa cinta yang tepat kepada anak (Gary Chapman \& Campbell, 2016). Bahasa cinta merupakan sebuah konsep sudut pandang terhadap kebutuhan oleh sepasang individu dalam usaha menjalin hubungan. Menurut Chapman (2010), Bahasa cinta terdiri dari lima Bahasa yang dapat digunakan oleh individu, yaitu: Words of Afirmation (Pemberian kata-kata positif), Quality Time (pemberian perhatian saat bersama individu lain), Acts of Service (pemberian bantuan dari pasangan), Receiving Gifts (pemberian hadiah kepada pasangan), dan Psychical Touch (pemberian rasa aman dan dicintai berupa sentuhan fisik). Kelima Bahasa cinta tersebut tidak semuanya ditemukan dalam individu namun hanya salah satu yang lebih dominan.

Selain orang tua harus peduli terhadap anak, orang tua juga harus mengamati segala hal yang berkaitan dengan anak (Irma, Nisa, \& Sururiyah, 2019). Orang tua yang memiliki tingkat pengetahuan dan pemahaman yang baik akan dapat memberikan pemantauan dan pelatihan anak untuk perkembangan yang optimal sehingga jika terdapat tumbuh kembang yang abnormal dapat dideteksi sedari dini (Noviyani, Jayatmi, \& Herliana, 2018). Dalam kajian ini terutama kepada apa yang anak sukai dan tidak disukai. Orang tua harus mengetahui minat dan bakat anak terlebih dahulu. Ketika orang tua mengetahui minat dan bakat anak, orang tua dapat mengarahkan minat tersebut kepada hal positif yang tentunya masih sesuai dengan kegemaran anak (Vance \& Brandon, 2017).

\section{Metode Pelaksanaan}

Kegiatan ini melibatkan sebanyak 47 ibu-ibu yang tergabung dalam komunitas RPTRA dan telah memiliki anak sebagai peserta audiens. Kegiatan ini diadakan secara daring (online) pada tanggal 8 bulan Januari tahun 2021 yang dimulai dari pukul 09.00 hingga pukul 12.00 . Metode yang digunakan dalam kegiatan ini yaitu metode ceramah yang ditampilkan dalam pemaparan materi interaktif melalui pengajaran (Djudin, 2018) mengenai cara menjadi orang tua yang cool, yang dimana dalam kegiatan kali ini akan dibahas melalui aspek kepedulian dan pengamatan. 

Perdini

Kegiatan juga dilakukan dengan menjawab pertanyaan secara langsung, baik dari audiens maupun dari pemateri. Sebelum materi edukasi diberikan kepada auidiens, audiens diberikan lembar pertanyaan mengenai pengetahuannya terkait pengasuhan dan perkembangan anak, kusioner pre-test diberikan untuk mengetahui gambaran awal mengenai pengetahuan audiens tentang pengasuhan serta perkembangan anak. Setelah materi edukasi dipaparkan kepada audiens diberikan lagi lembar pertanyaan post-test, yang berisikan pertanyaan yang sama. Tujuannya yaitu untuk melihat apakah edukasi yang diberikan memberikan tambahan pengetahuan kepada para audiens atau tidak. Langkah-langkahnya adalah sebagai berikut a) Pemberian lembar pertanyaan pre-test; b) Pemberian materi "caring" oleh ibu Yuarini Wahyu Pertiwi., S.Psi., S.H., M.Psi., Psikolog; c) Pemberian materi "observing" oleh ibu Hema Dayita Pohan, S.Psi., M.Psi., Psikolog; d) Diskusi dan Tanya-jawab; e) Pemberian lembar pertanyaan post-test; f) Penutup.

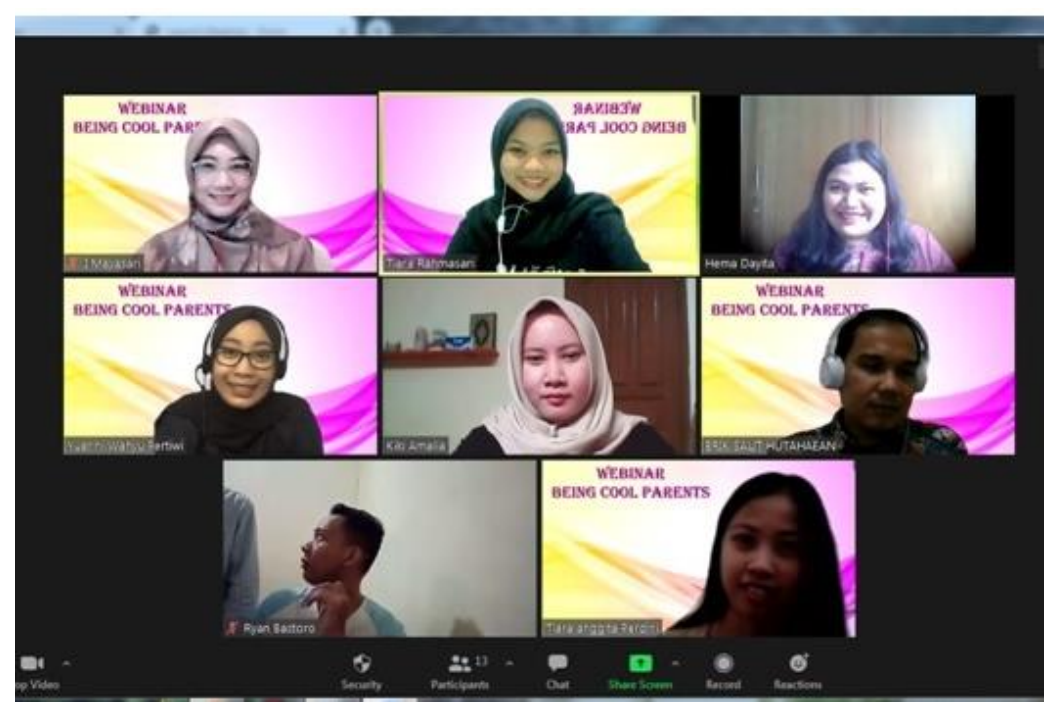

Sumber: Hasil Pelaksanaan (2021)

Gambar 1. Tim Pelaksana Beserta Narasumber Dalam Acara

\section{Hasil dan Pembahasan}

\subsection{Persiapan}

Sebelum kegiatan pengabdian dijalankan, tim pelaksana terlebih dahulu mendatangi RPTRA untuk mendapatkan gambaran lokasi mengenai keadaan lingkungan, dan informasi tambahan lainnya. Dari kegiatan tersebut, tim pelaksana memutuskan untuk mengangkat tema pengasuhan, mengingat RPTRA merupakan komunitas yang dibentuk untuk membangun kenyamanan anak dan orang tua. Pengangkatan tema ini juga didasari dari hasil wawancara singkat tim pelaksana kepada orang tua yang tergabung di RPTRA. Dari hasil wawancara, kebanyakan orang tua mengeluh mengenai sifat dan sikap anaknya, contohnya seperti susah diatur, susah diajak berbicara, tidak sepemikiran dan masih tertanam rasa egois. Oleh sebab itu dibutuhkan informasi dan pengetahuan yang dapat menambah ilmu orang tua mengenai 
pengasuhan yang baik kepada anak, sehingga kedepannya diharapkan anak dan orang tua dapat menemukan jalan tengah dari permasalahan-permasalahan tersebut.

\subsection{Deskripsi subjek}

Pelaksanaan kegiatan dikoordinasikan oleh tim pelaksana dan dihadiri oleh para pengurus RPTRA, Tamu undangan, dan para peserta (audiens) yang dalam kegiatan ini adalah ibu-ibu. Pada tabel 1 terdapat gambaran deskripsi para peserta yang menghadiri kegiatan ini.

Tabel 1. Gambaran Subjek

\begin{tabular}{ccccccccccc}
\hline & \multicolumn{4}{c}{ Usia } & \multicolumn{4}{c}{ Pendidikan Terakhir } & \multicolumn{4}{c}{ Pekerjaan } \\
\hline $25-35$ & $36-45$ & $46-55$ & $56-70$ & SMA & S1 & S2 & Dosen & Guru & Karyawan Swasta & Ibu Rumah Tangga \\
\hline 8 & 13 & 21 & 5 & 27 & 19 & 1 & 1 & 3 & 4 & 39 \\
\hline
\end{tabular}

Sumber: Hasil Pelaksanaan (2021)

Dapat dilihat pada tabel 1 bahwa peserta yang menghadiri kegiatan ini berjumlah 47 orang yang semuanya adalah ibu-ibu. Deskripsi peserta dapat dilihat dalam 3 kelompok, yaitu berdasarkan usia, pendidikan terakhir dan profesi pekerjaan. Dalam kelompok usia, peserta yang berusia 25-35 tahun berjumlah 8 orang, peserta berusia 36-45 tahun berjumlah 13 orang, peserta dengan usia 46-55 tahun berjumlah 21 orang dan peserta dengan usia 56-70 tahun berjumlah 5 orang. Jika dilihat pada kelompok pendidikan terakhir maka peserta dengan lulusan SMA sederajat berjumlah 27 orang, peserta dengan lulusan S1 berjumlah 19 orang dan peserta dengan lulusan S2 berjumlah 1 orang. Pada status pekerjaan juga dapat dilihat bahwa rata-rata peserta dalam kegiatan ini adalah murni ibu rumah tangga yang tidak bekerja, yaitu sebanyak 39 orang dari 47 orang.

\subsection{Pelaksanaan kegiatan}

Sebelum kegiatan pemaparan dilaksanakan, peserta terlebih dahulu diberikan lembar pertanyaan pre-test. Lembar pertanyaan pre-test berisikan empat pertanyaan mengenai pengetahuan caring, dan observing para orang tua terhadap anaknya. Empat pertanyaan tersebut dapat dilihat pada tabel dibawah ini

Tabel 2. Pertanyaan Kuesioner

\begin{tabular}{lc}
\hline No & Pertanyaan \\
\hline 1 & Apa yang anda ketahui tentang bahasa kasih sayang? \\
\hline 2 & Apa yang biasanya Anda lakukan untuk mengungkapkan kasih sayang ke anak? \\
\hline 3 & Apa yang anda ketahui tentang tugas perkembangan anak? \\
\hline 4 & Berdasarkan pengamatan selama ini bagaimanakah perkembangan anak Anda? \\
\hline Sumber: Hasil Pelaksanaan (2021)
\end{tabular}

Sumber: Hasil Pelaksanaan (2021)

Pertanyaan yang disediakan pada tabel 2, merupakan pertanyaan caring dan observing (nomor 1,2 terkait caring, nomor 3,4 terkait observing). Setelah mengisi lembar pre-test, kemudian lanjut kepada kegiatan pemaparan materi yang disampaikan oleh ibu Yuarini Wahyu Pertiwi., S.Psi., S.H., M.Psi., Psikolog (pemateri caring), dan ibu Hema Dayita Pohan, S.Psi., M.Psi., Psikolog (pemateri observing). Dalam kegiatan pemaparan materi caring, pemateri menjelaskan pengertian kasih sayang dan bagaimana menunjukan kasih sayang kepada anak, selain itu dijelaskan juga mengenai Bahasa cinta yang didasari dari teori Chapman (2010). Melalui 

Perdini

materi observing dijelaskan juga mengenai tugas perkembangan anak berdasarkan masingmasing usianya dan bagaimana cara mengamati anak dengan baik dan benar. Setelah pemaparan materi, peserta diberikan lagi lembar jawaban post-test yang dimana pertanyaannya disusun sama persis dengan pre-test

Tabel 3. Jawaban Audiens

\begin{tabular}{|c|c|c|c|c|}
\hline & $\begin{array}{c}\text { Apa yang anda } \\
\text { ketahui tentang } \\
\text { bahasa kasih sayang? }\end{array}$ & $\begin{array}{c}\text { Apa yang biasanya } \\
\text { Anda lakukan untuk } \\
\text { mengungkapkan kasih } \\
\text { sayang ke anak? }\end{array}$ & $\begin{array}{l}\text { Apa yang anda ketahui } \\
\text { tentang tugas } \\
\text { perkembangan anak? }\end{array}$ & $\begin{array}{c}\text { Berdasarkan pengamatan } \\
\text { selama ini bagaimanakah } \\
\text { perkembangan anak } \\
\text { Anda? }\end{array}$ \\
\hline $\begin{array}{l}\text { Pre- } \\
\text { Test }\end{array}$ & $\begin{array}{l}\text { Mengungkap kata } \\
\text { pujian, mengasihi } \\
\text { menyayangi, Bahasa } \\
\text { hati, komunikasi dua } \\
\text { arah, ungkapan } \\
\text { perasaan melalui } \\
\text { tindakan, kedekatan } \\
\text { dengan anak }\end{array}$ & $\begin{array}{l}\text { Memeluk, mencium, } \\
\text { memberi hadiah, } \\
\text { menasehati, } \\
\text { memperhatikan } \\
\text { kebutuhan anak, } \\
\text { mengusap kepala }\end{array}$ & $\begin{array}{c}\text { Sudah mengetahui } \\
\text { tanggung jawab, pola asuh } \\
\text { sesuai usia anak, dapat } \\
\text { menyesuaikan diri dengan } \\
\text { temannya, memantau } \\
\text { pekembangan anak baik } \\
\text { fisik maupun psikis, } \\
\text { memberikan pendidikan } \\
\text { yang baik }\end{array}$ & $\begin{array}{l}\text { Bagus, normal, sesuai } \\
\text { usianya, sehat, kurang } \\
\text { percaya diri, sering } \\
\text { menghabiskan waktu di } \\
\text { sosmed, cemburu dengan } \\
\text { saudaranya }\end{array}$ \\
\hline $\begin{array}{l}\text { Post- } \\
\text { Test }\end{array}$ & $\begin{array}{l}\text { Mengungkap kata } \\
\text { pujian, komunikasi } \\
\text { dua arah, ungkapan } \\
\text { perasaan melalui } \\
\text { tindakan, kedekatan } \\
\text { dengan anak }\end{array}$ & $\begin{array}{l}\text { Memeluk, mencium, } \\
\text { memberi hadiah, } \\
\text { memperhatikan } \\
\text { kebutuhan anak, } \\
\text { mengusap kepala, } \\
\text { meluangkan waktu, } \\
\text { mengobrol, memuji }\end{array}$ & $\begin{array}{l}\text { dapat menyesuaikan diri } \\
\text { dengan temannya, } \\
\text { memantau pekembangan } \\
\text { anak baik sosial, fisik } \\
\text { maupun psikis, memahami } \\
\text { perkembangan anak }\end{array}$ & $\begin{array}{l}\text { Bagus, normal, sesuai } \\
\text { usianya, sehat, sering } \\
\text { menghabiskan waktu di } \\
\text { sosmed, cemburu dengan } \\
\text { saudaranya, lebih banyak } \\
\text { main diluar rumah, sesuai } \\
\text { ekspetasi orang tua }\end{array}$ \\
\hline
\end{tabular}

Sumber: Hasil Pelaksanaan (2021)

Hasil kuesioner mengenai caring dan observing, baik pre-test maupun post-test tidak memiliki perbedaan yang signifikan. seperti yang dapat dilihat pada tabel 3 , terkumpul jawaban peserta yang lebih tepat pada jawaban post-test. Terdapat penambahan jawaban dan pengurangan jawaban. Seperti pada pertanyaan "apa yang anda ketahui tentang Bahasa kasih sayang", telah hilang jawaban 'mengasihi menyayangi dan Bahasa hati'. Pada pertanyaan "Apa yang biasanya Anda lakukan untuk mengungkapkan kasih sayang ke anak?", telah hilang jawaban 'menasehati' dan muncul jawaban baru yaitu 'meluangkan waktu, mengobrol dan memuji'. Kemudian pada pertanyaan "Apa yang anda ketahui tentang tugas perkembangan anak?", hilang jawaban 'mengetahui tanggung jawab, pola asuh sesuai usia dan memberikan pendidikan kepada anak' yang digantikan dengan jawaban 'memahami perkembangan anak'. Lalu pertanyaan terakhir yaitu "Berdasarkan pengamatan selama ini bagaimanakah perkembangan anak Anda?", hilangnya jawaban 'kurang percaya diri' dan bertambah jawaban 'lebih banyak main diluar rumah'.

\subsection{Manfaat bagi para peserta}

Melalui kegiatan ini, para orang tua bisa mendapatkan pengetahuan yang lebih banyak lagi mengenai pengasuhan terhadap anak. Selain itu para peserta juga dapat mengevaluasi diri terkait 'apakah pendekatan cinta kepada anaknya sudah terjalin?', 'apakah selama ini, sebagai 
orang tua sudah memperhatikan anaknya dengan baik?'. Sehingga para peserta dapat mengetahui langkah-langkah apa saja yang bisa diambil dalam mendekatkan diri kepada anakanaknya. Inilah salah satu manfaat yang dapat diambil dari kegiatan ini yaitu menanamkan nilai-nilai pengasuhan yang baik bagi para orang tua

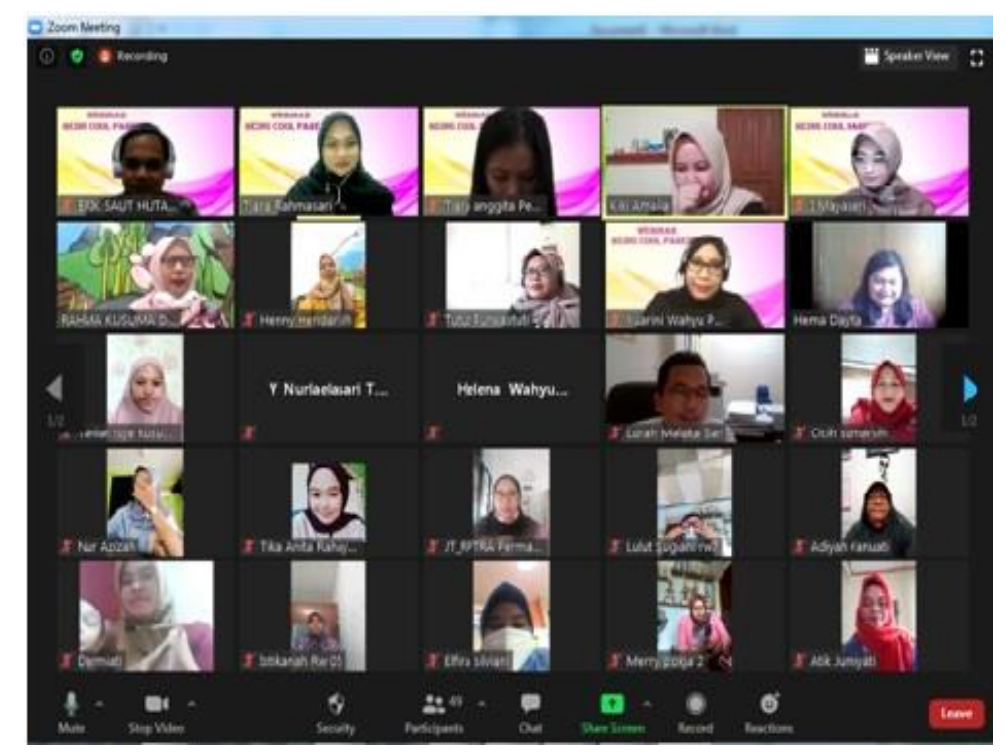

Sumber: Hasil Pelaksanaan (2021)

Gambar 2. Kegiatan Pengabdian Masyarakat Yang Dilakukan Secara Daring

\section{Kesimpulan}

Pengetahuan mengenai pengasuhan (caring, observing) yang telah disampaikan dalam kegiatan ini bisa memberikan tambahan pemahaman kepada para peserta. Materi yang telah disampaikan oleh pembicara (narasumber) dapat memberikan tambahan sikap apa saja yang dapat menyampaikan rasa kasih sayang, dan hal apa saja yang harus diperhatikan dari si anak. Kegiatan ini telah memberikan manfaat dalam menambahkan pemahaman dan pengetahuan peserta mengenai kasih sayang dan perhatian orang tua kepada anak. Kegiatan ini masih terbatas kepada tingkat pengetahuan dan pemahaman, oleh sebab itu masih diperlukan kegiatan tindak lanjut yang dapat memberikan rangsangan tambahan sehingga diharapkan orang tua tidak sekedar mengetahui dan memahami pengasuhan yang baik namun juga dapat secara langsung mempraktekannya. Bagi pemerintah, khususnya para pengurus RPTRA alangkah baiknya jika dapat membuat program-program tambahan mengenai kelekatan anak dan orang tua.

\section{Daftar Pustaka}

Benson, P. L., Roehlkepartain, E. C., \& Rude, S. P. (2003). Spiritual development in childhood and adolescence: Toward a field of inquiry. Applied Developmental Science, 7(3), 205213. https://doi.org/10.1207/S1532480XADS0703_12

Chapman, G. (2010). The 5 love languages: The secret to love that last. Chicago: Northfield Publishing. 
Yuarini Wahyu Pertiwi, Hema Dayita Pohan, Erik Saut H Hutahaean, Djuni Thamrin, Tiara Anggita Perdini

Chapman, G., \& Campbell, R. (2016). The 5 Love Languages of children: The Secret to loving children effectively. Moody Publishers.

Djudin, T. (2018). The Effect of Teaching Method and Lecture Program on Students' Satisfaction Rates and Academic Achievement. JETL (Journal Of Education, Teaching and Learning), 3(1), 121. https://doi.org/10.26737/jetl.v3i1.322

Holcomb, J., Latham, K., \& Fernandez-Baca, D. (2015). Who Cares for the Kids? Caregiving and Parenting in Disney Films. Journal of Family Issues, 36(14), 1957-1981. https://doi.org/10.1177/0192513X13511250

Hutahaean, E. S. H., Nugraha, A. C. W., Perdini, T. A., Bastoro, R., \& Marbun, R. (2020). Analisis Pola Asuh, Kontrol Diri, dan Moralitas Kepribadian sebagai faktor Kenakalan Remaja di Kota Bekasi. Jurnal Psikologi, 16(1), 11-23. https://doi.org/http://dx.doi.org/10.24014/ jp.v14i2.7812

Irma, C. N., Nisa, K., \& Sururiyah, S. K. (2019). Keterlibatan Orang Tua dalam Pendidikan Anak Usia Dini di TK Masyithoh 1 Purworejo. Jurnal Obsesi : Jurnal Pendidikan Anak Usia Dini, 3(1), 214. https://doi.org/10.31004/obsesi.v3i1.152

Khaulani, F., Neviyarni, \& Murni, I. (2020). Fase Dan Tugas Perkembangan Anak Sekolah Dasar. Jurnal Ilmiah Pendidikan Dasar, 7(1), 51. https://doi.org/10.30659/pendas.7.1.5159

Lafollette, H. (2010). Licensing parents revisited. Journal of Applied Philosophy, 27(4), 327343. https://doi.org/10.1111/j.1468-5930.2010.00497.x

Moore, R. C. (2017). Childhood's Domain (Child Deve). New York: Routledge.

Noviyani, E. P., Jayatmi, I., \& Herliana, I. (2018). Hubungan Peran Orang Tua dan Pola Asuh Makan terhadap Perkembangan Balita. Jurnal IImiah Kebidanan Indonesia, 8(1), 1-7. https://doi.org/10.33221/jiki.v8i1.86

Ruang Publik Terpadu Ramah Anak (RPTRA). (2020, November 30). Jakarta.go.id. Retrieved from https://jakarta.go.id/artikel/konten/7159/ruang-publik-terpadu-ramah-anak-rptra

Santrock, J. . (2003). Adolescence Perkembangan Remaja (6th ed.). Jakarta: Erlangga.

Santrock, J. W. (2012). Life-Span Development (Perkembangan Masa Hidup) (13th ed.). Jakarta: Erlangga.

Susanti, S., \& Koswara, I. (2019). Concept of Silih Asih, Silih Asah, Silih Asuh In The Aculturation In Bamdung. Advances in Social Science, Education and Humanities Research (ASSEHR), 140(ISCoGI 2017), 13-17. https://doi.org/10.2991/iscogi-17.2019.4

Suteja, J. (2017). Dampak Pola Asuh Orang Tua Terhadap Perkembangan Sosial-Emosional Anak. 3(1). https://doi.org/10.24235/awlady.v3i1.1331

Vance, A. J., \& Brandon, D. H. (2017). Delineating among parenting confidence, parenting selfefficacy, and competence. Advances in Nursing Science, 40(4), E18-E37. https://doi.org/10.1097/ANS.0000000000000179

Winnicott, D. W. (2021). The Child, The Family, and the outside world. Penguin UK. 